Article

\title{
Performance Problem of Current Differential Protection of Lines Emanating from Photovoltaic Power Plants
}

\author{
Yingyu Liang ${ }^{1, * \mathbb{D}}$, Wulin $\mathrm{Li}^{1}{ }^{\mathbb{D}}$ and Guanjun $\mathrm{Xu}^{2}$ \\ 1 School of Mechanical Electronic and Information Engineering, China University of Mining and Technology, \\ Beijing 100083, China; 1mmx1995@163.com \\ 2 NARI Group Corporation (State Grid Electric Power Research Institute), Nanjing 211000, China; \\ XuGuanJun8555@163.com \\ * Correspondence: liangyingyu2013@163.com; Tel.: +86-010-62331370
}

Received: 14 January 2020; Accepted: 11 February 2020; Published: 14 February 2020

\begin{abstract}
The amplitude and phase angle of the fault current in photovoltaic power plants (PVPPs) are significantly influenced by the control system of the grid-connected inverters, unlike in a conventional synchronous source. Hence, PVPPs may adversely affect the performance of the current differential protection designed for synchronous sources-based power grids. In order to study the performance problem of current differential protection on AC transmission lines, an analytical expression of the fault current in the PVPPs was deduced, and the fault current characteristic was extensively analyzed. Based on this analysis, the ratio of differential current over restraint current was initially derived in this study; this ratio is observed to be affected by the control system parameters, power grid system parameters, fault resistance, and fault types. Moreover, the dynamic characteristics of this ratio can be clearly observed based on a three-dimensional diagram. Furthermore, the operating performance of the current differential protection was analyzed under different influencing factors. The mathematical analysis presents that the amplitude ratio of the fault current on both sides of the line is larger than nine and that current differential protection will operate reliably in any case. Meanwhile, the theoretical analysis and simulation results show that the current phase angle difference may become an obtuse angle in case of an ungrounded fault, which will cause inaccurate operation of the current differential protection. The results of this study will provide guidance for the engineering application of current differential protection in case the PVPPs are connected to a power grid.
\end{abstract}

Keywords: current differential protection; fault current behavior; performance problem; photovoltaic power plants

\section{Introduction}

Photovoltaic (PV) power generators are extensively employed in the existing power networks as an effective solution to manage the increasing fossil fuel crisis and environmental pollution [1-4]. However, unlike conventional synchronous sources, the fault current amplitude and phase angle for the photovoltaic power plants (PVPPs) are significantly influenced by the control system of the grid-connected inverters, fault resistance, and fault types [5-8]. Therefore, this may cause the malfunctioning of the traditional relay protection of the lines emanating from the PVPPs [9-11]. With the maturity of the inverter integration technology and the commissioning of large-scale PVPPs, investigation of the impact of PVPPs on traditional relay protection exhibits considerable significance with respect to power grids.

Recently, numerous studies have investigated the influence of renewable energy power plants on conventional relay protection schemes. The fault currents within the PVPP based on a short-circuit test 
are analyzed in reference [12]. Moreover, the operation performance of the existing protection scheme was evaluated. Considering the specific fault characteristics of the PVPPs, the impact of the PVPPs on the fault component distance protection of transmission lines was mathematically analyzed in reference [13]. The simulation results showed that the line protection may operate incorrectly in case of internal faults. By comparing field test results with theoretical analysis, the operation performance of existing overcurrent relay (OCR) was evaluated in reference [14]. They discovered that the OCRs at the PV side on overhead lines may fail to operate. Hence, a new relay scheme based on directional distance elements was proposed. Furthermore, some studies have briefly analyzed the impact of PVPPs on the conventional relay protection of the AC transmission lines [15,16]. Some previous studies [17-19] reveal that the conventional distance protection exhibits a high risk of malfunction or inoperability with respect to the interconnection of the inverter-interfaced renewable energy generators (IIREGs). Moreover, with the rapid development of the wind farms, large-scale wind farms are extensively employed in the power grid system, and the influence of wind farms on conventional distance relay was investigated in reference [20]. Although numerous studies have studied the influence of IIREGs on conventional distance protection [12-20], the effect of current differential protection has not been discussed in these studies.

Current differential protection is usually considered to constitute the primary protection for high-voltage transmission lines and is more sensitive and faster than distance protection [21-23]. Currently, only some studies have investigated the impact of the renewable energy power plants (REPPs) on current differential protection. The fault-current expression of the permanent magnet synchronous generators was deduced in a previously conducted study [24]. The study showed that current differential protection may not operate appropriately because the fault-current phase angles of the wind farm significantly deviate from those of the conventional synchronous source. However, the mathematical expression of the ratio of differential current over restraint current could not be derived and its dynamic characteristics could not be analyzed. In reference [25], a new differential protection method was presented for the tapped transmission line connected with a unified power flow controller (UPFC) and wind farms; however, the effect of UPFC and wind farms on the operating performance of current differential protection was not theoretically analyzed. A mathematical equivalent model of the inverter-interfaced generators (IIGs) was established in reference [26]; based on this analysis, a new virtual multi-terminal current differential protection method was presented. The simulation and test results denoted that the presented protection will perform well under various fault conditions. The performance analysis of the traditional current differential protection is considerably influenced by the interconnection of the inverter-interfaced generators (IIGs), and a novel current differential protection based on sequence component was presented in a previously conducted study [27]. However, the literature $[26,27]$ does not theoretically analyze the impact of various influencing factors on the current differential protection. A new protection method will operate reliably in case of a high-resistance fault or weak infeed of the distribution generators (DGs) [28]. However, the previously conducted studies simply describe the fault current characteristics of DGs and do not obtain the theoretical derivation of the effects of DGs on current differential protection. This protection method is only applicable to DGs. Therefore, some studies analyzed current differential protection [24-28]; however, PVPPs differ from wind farms and DGs in terms of their operation mode and control strategy. In addition, the influence of the control system parameters, power grid system parameters, fault resistance, and fault types on the current differential protection have not been studied in the literature, and this issue will be discussed in detail herein. Hence, studying the performance problem of current differential protection on the high-voltage transmission lines is crucial.

Some studies have briefly analyzed the fault characteristics of PVPPs and focused on the impact of PVPPs on distance protection [12-16]. However, current differential protection differs from distance protection from the viewpoints of working principle and operation criterion. Furthermore, even though previous studies have investigated the influence of REPPs on current differential protection [24-28], they have not discussed the specific fault characteristics of PVPPs or conducted an analysis from a 
mathematical viewpoint. When compared with previous studies, this study is the first to derive the mathematical expression of the ratio of differential current over restraint current, and its dynamic characteristics are analyzed. Furthermore, this study analyzes the influence of PVPPs on the current differential protection of AC transmission lines based on the mathematical theory and summarizes its influencing factors based on the analytical expressions. Finally, the accuracy of the theoretical analysis was validated using PSCAD.

\section{Fault Current Characteristics}

\subsection{Overview of the PV Power Plants}

Current differential protection plays an important role in ensuring the security of the AC transmission line, and this section presents advantages of high reliability and sensitivity [22,23]. To effectively analyze the impact of the PVPPs on the current differential protection of the AC transmission lines, the partial topology of the PVPPs is illustrated in Figure 1. The PVPPs use a two-stage boost structure to connect with the power grid. First, a centralized photovoltaic inverter was used to convert the direct current into alternating current; subsequently, a 220-kV double-winding transformer was transmitted via a 35-kV collector line. Finally, the power output was boosted and transmitted to the power system through a step-up substation. Generally, a PVPP collects many PV units. A single PV unit has a capacity of $1 \mathrm{MWp}$ and includes two $500 \mathrm{~kW}$ centralized photovoltaic inverters. The M-side denotes the PVPP side, whereas the N-side denotes the system side.

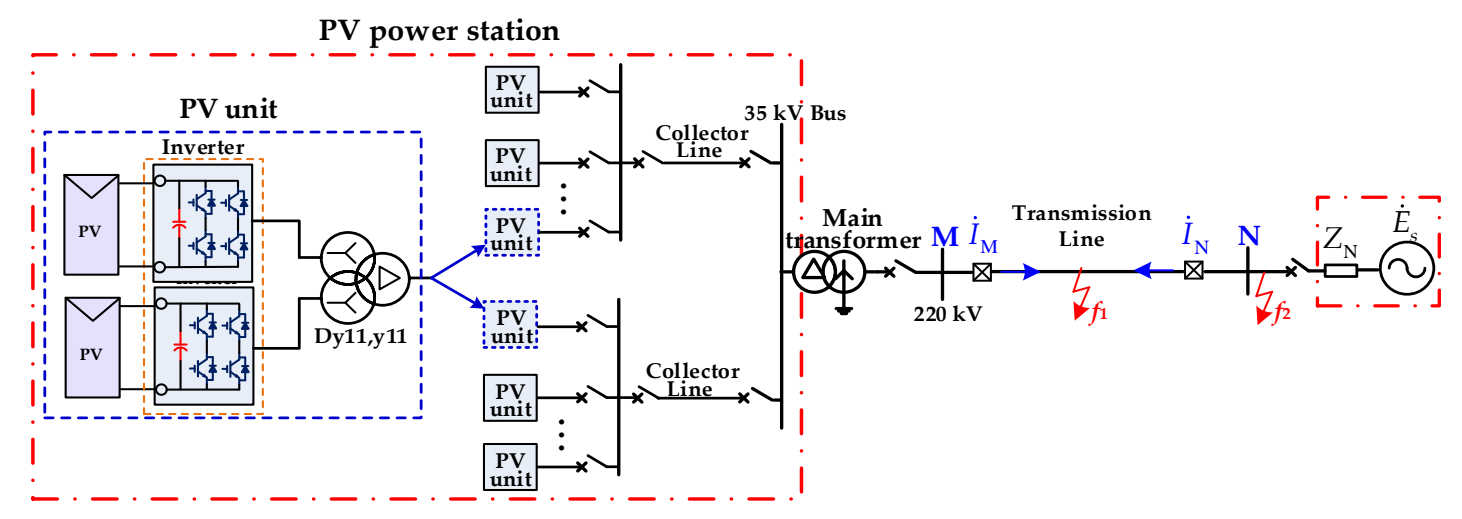

Figure 1. Partial topology of a photovoltaic power plant (PVPP).

\subsection{Ground Short-Circuit Faults}

In this section, the fault current features of the $\mathrm{M}$ - and $\mathrm{N}$-sides are analyzed by considering the internal phase-A-to-ground (AG) fault as an example. Similarly, the analytic processes and conclusions for the AG fault can be applied to other asymmetric ground faults.

When the AG fault happen at the high-voltage transmission lines, the three-phase voltage phasors of the M-side in the transmission line can be given by

$$
\dot{U}_{\mathrm{M} x}=\dot{U}_{\mathrm{M} x 1}+\dot{U}_{\mathrm{M} x 2}+\dot{U}_{\mathrm{M} x 0}=U_{1} \measuredangle\left(\delta_{1}+\delta_{x}\right)+U_{2} \measuredangle\left(\delta_{2}-\delta_{x}\right)+U_{0} \measuredangle \delta_{0}
$$

where the superscripts " 1, " " 2, " and " 0 " represent the positive-, negative-, and zero-sequence components, respectively. $U_{1}, U_{2}$, and $U_{0}$ denote the positive-, negative-, and zero-sequence voltage amplitudes, respectively. $\delta_{1}, \delta_{2}$, and $\delta_{0}$ denote the positive-, negative-, and zero-sequence voltage initial phases, respectively. $x=\mathrm{a}, \mathrm{b}$, and $\mathrm{c} ; \delta_{\mathrm{a}}=0^{\circ} ; \delta_{\mathrm{b}}=-120^{\circ}$; and $\delta_{\mathrm{c}}=120^{\circ}$.

Owing to the fast response speed of the PV inverter, the current controller can ensure that the reference current quickly tracks the actual output current within $10 \mathrm{~ms}$. Therefore, the dynamics of the PV inverter will not be considered in the following theoretical analysis [7,17]. In case of an asymmetric 
fault happens at the high-voltage transmission line, the following unified expression of the current references can be obtained under various control targets [13,29]:

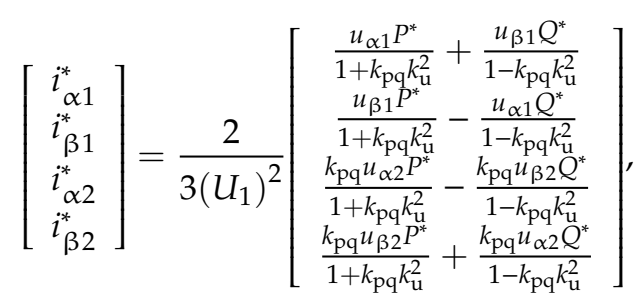

where $k_{\mathrm{pq}}$ is target coefficient that represents the control targets under the fault-ride-through period. When $k_{\mathrm{pq}}=-1,0$, and 1 , the control target is to eliminate the active power oscillation, negative-sequence current, and reactive power oscillation, respectively. $P^{*}$ and $Q^{*}$ are the active and reactive power references, respectively, and $k_{\mathrm{u}}$ is the grid voltage imbalance coefficient $\left(k_{\mathrm{u}}=U_{2} / U_{1}\right)$.

Based on the current references determined by Equation (2), In the event of an asymmetric fault, the following positive and negative sequence components in the M-side fault current can be calculated:

$$
\begin{gathered}
\dot{I}_{\mathrm{M} x 1}=I_{\mathrm{Mm} 1} \measuredangle \varphi_{x 1}=I_{\mathrm{Mm} 1} \measuredangle\left(\delta_{1}+\varphi+\delta_{x}\right) \\
\dot{I}_{\mathrm{M} x 2}=k_{\mathrm{pq}} k_{\mathrm{u}} I_{\mathrm{Mm} 1} \measuredangle \varphi_{x 2}=k_{\mathrm{pq}} k_{u} I_{\mathrm{Mm} 1} \measuredangle\left(\delta_{2}+\varphi-\delta_{x}\right)
\end{gathered},
$$

where $I_{\mathrm{Mm} 1}$ is the amplitude of the positive-sequence component in the M-side fault current and $\varphi_{x 1}$ and $\varphi_{x 2}$ are the phase angles of the positive- and negative-sequence component in the M-side fault current, respectively.

$$
\begin{gathered}
I_{\mathrm{Mm} 1}=\frac{2}{3 u_{1}} \sqrt{\left(\frac{P^{*}}{1+k_{\mathrm{pq}} k_{\mathrm{u}}^{2}}\right)^{2}+\left(\frac{Q^{*}}{1-k_{\mathrm{pq}} k_{\mathrm{u}}^{2}}\right)^{2}}, \\
\varphi=\tan ^{-1} \frac{-Q^{*}\left(1+k_{\mathrm{pq}} k_{\mathrm{u}}^{2}\right.}{P^{*}\left(1-k_{\mathrm{pq}} k_{\mathrm{u}}^{2}\right)}
\end{gathered}
$$

Figure 2 illustrates the sequence network diagram under the AG fault at $f_{1}$. Where the $Z_{\mathrm{L} 1}, Z_{\mathrm{L} 2}$ and $Z_{\mathrm{L} 0}$ represent the positive-, negative-, and zero-sequence impedance of the line, respectively. The $\dot{I}_{\text {fa1 }}$, $\dot{I}_{\text {fa2 }}$ and $\dot{I}_{\text {fa0 }}$ represent the positive-, negative-, and zero-sequence currents injected into the fault location, respectively. The $\dot{I}_{\mathrm{Ma} 1}, \dot{I}_{\mathrm{Ma} 2}$ and $\dot{I}_{\mathrm{Ma} 0}$ represent the positive-, negative-, and zero-sequence component in the M-side fault current, respectively. The $\dot{I}_{\mathrm{Na} 1}, \dot{I}_{\mathrm{Na} 2}$ and $\dot{I}_{\mathrm{Na} 0}$ represent the positive-, negative-, and zero-sequence component in the $\mathrm{N}$-side fault current, respectively. The $Z_{\mathrm{T} 1}, Z_{\mathrm{T} 2}$ and $Z_{\mathrm{T} 0}$ represent the positive-, negative-, and zero-sequence reactance of the transformer, respectively. The $Z_{\mathrm{N} 1}, Z_{\mathrm{N} 2}$ and $Z_{\mathrm{N} 0}$ represent the positive-, negative-, and zero-sequence reactance of power grid, respectively.

Due to the weak feed characteristics of PVPPs and the controllability of grid-connected inverters, the amplitudes of the positive- and negative-sequence component in the M-side fault current are significantly lower when compared with those in the N-side fault current; therefore,

$$
\dot{I}_{\mathrm{Na} 1} \approx \dot{I}_{\mathrm{fa} 1}, \dot{I}_{\mathrm{Na} 2} \approx \dot{I}_{\mathrm{fa} 2}
$$

In case of the AG fault, the positive-, negative-, and zero-sequence currents injected into the fault location $\left(f_{1}\right)$ are equal and can be expressed:

$$
\dot{I}_{\mathrm{fa} 1}=\dot{I}_{\mathrm{fa} 2}=\dot{I}_{\mathrm{fa} 0} \approx \frac{\dot{U}_{\mathrm{f}|0|}}{\mathrm{Z}_{\Sigma 1}+\mathrm{Z}_{\Sigma 2}+\mathrm{Z}_{\Sigma 0}+3 R_{\mathrm{f}}}=\frac{U_{\mathrm{f}|0| \measuredangle 0^{0}}}{\left|\mathrm{Z}_{\Sigma}^{\mathrm{AG}}\right| \measuredangle \theta_{\mathrm{Z}-\mathrm{AG}}}=\frac{U_{\mathrm{f}|0|}}{\left|\mathrm{Z}_{\Sigma}^{\mathrm{AG}}\right|} \measuredangle-\theta_{\mathrm{Z}-\mathrm{AG}},
$$

where $\dot{U}_{\mathrm{f}|0|}$ is the pre-fault voltage at $f_{1}, \mathrm{R}_{\mathrm{f}}$ is the fault resistance, and $Z_{\Sigma 1}, Z_{\Sigma 2}$, and $Z_{\Sigma 0}$ are the total impedance of the positive-, negative- and zero-sequence network, respectively. $Z_{\Sigma}^{\mathrm{AG}}$ and $\theta_{\mathrm{Z} \text {-AG }}$ are the total impedance and impedance angle of the AG fault network, respectively. 
As depicted in Figure 2, the zero-sequence current on the M- and N-sides of the transmission line $\mathrm{MN}$ can be gained,

$$
\begin{gathered}
\dot{I}_{\mathrm{Ma} 0}=\frac{(1-\alpha) Z_{\mathrm{L} 0}+Z_{\mathrm{N} 0}}{Z_{\mathrm{T} T}+Z_{\mathrm{L} 0}+Z_{\mathrm{N} 0}} \dot{I}_{\mathrm{fa} 0}=C_{\mathrm{M} 0} \dot{I}_{\mathrm{fa} 0} \\
\dot{I}_{\mathrm{Na} 0}=\frac{\alpha Z_{\mathrm{L} 0}+Z_{\mathrm{T} 0}}{Z_{\mathrm{T} 0}+Z_{\mathrm{L} 0}+Z_{\mathrm{N} 0}} \dot{I}_{\mathrm{fa} 0}=\left(1-C_{\mathrm{M} 0}\right) \dot{I}_{\mathrm{fa} 0}
\end{gathered},
$$

where $\alpha$ is the ratio of the distance from the fault location to the bus $\mathrm{M}$ with respect to the length of the transmission line, and its value is $0-1$. Therefore, the value of $\alpha$ is dependent on the fault location. The $C_{\mathrm{M} 0}$ denotes the zero-sequence current distribution coefficient. Generally, the impedance angles of zero-sequence current in the $\mathrm{M}$ - and $\mathrm{N}$-sides are approximately equal, such that $C_{\mathrm{M} 0}$ is approximately a real number.

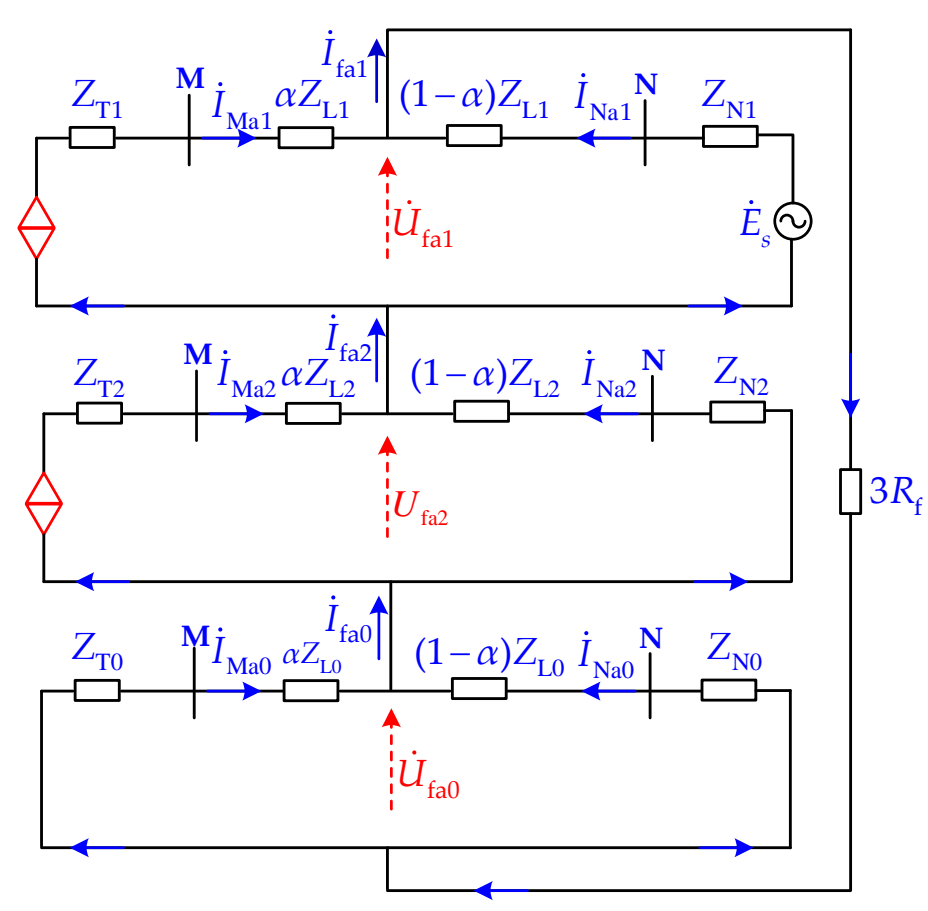

Figure 2. Sequence network diagram under the phase-A-to-ground (AG) fault at $f_{1}$.

Based on Equations (3), (5)-(7), the following phase-A current on the M- and N-sides can be calculated:

$$
\begin{gathered}
\dot{I}_{\mathrm{Ma}}=\dot{I}_{\mathrm{Ma} 1}+\dot{I}_{\mathrm{Ma} 2}+\dot{I}_{\mathrm{Ma} 0}=I_{\mathrm{Mml}} \measuredangle\left(\delta_{1}+\varphi\right)+k_{\mathrm{pq}} k_{u} I_{\mathrm{Mml}} \measuredangle\left(\delta_{2}+\varphi\right)+C_{\mathrm{M} 0} \frac{U_{\mathrm{f}|0|}}{\left|\mathrm{Z}_{\Sigma}^{\mathrm{AG}}\right|} \measuredangle-\theta_{\mathrm{Z}-\mathrm{AG}} \\
\dot{I}_{\mathrm{Na}}=\dot{I}_{\mathrm{Na} 1}+\dot{I}_{\mathrm{Na} 2}+\dot{I}_{\mathrm{Na} 0} \approx\left(3-C_{\mathrm{M} 0}\right) \frac{U_{\mathrm{f}|0|}}{\left|\mathrm{Z}_{\Sigma}^{\mathrm{AG}}\right|} \measuredangle-\theta_{\mathrm{Z}-\mathrm{AG}} .
\end{gathered}
$$

\subsection{Ungrounded Short-Circuit Faults}

In this section, the fault current features of the $\mathrm{M}$ - and $\mathrm{N}$-sides is analyzed by taking internal phase-B-to-phase-C (BC) fault as an example. Figure 3 illustrates the sequence network diagram under a BC fault at $f_{1}$. 


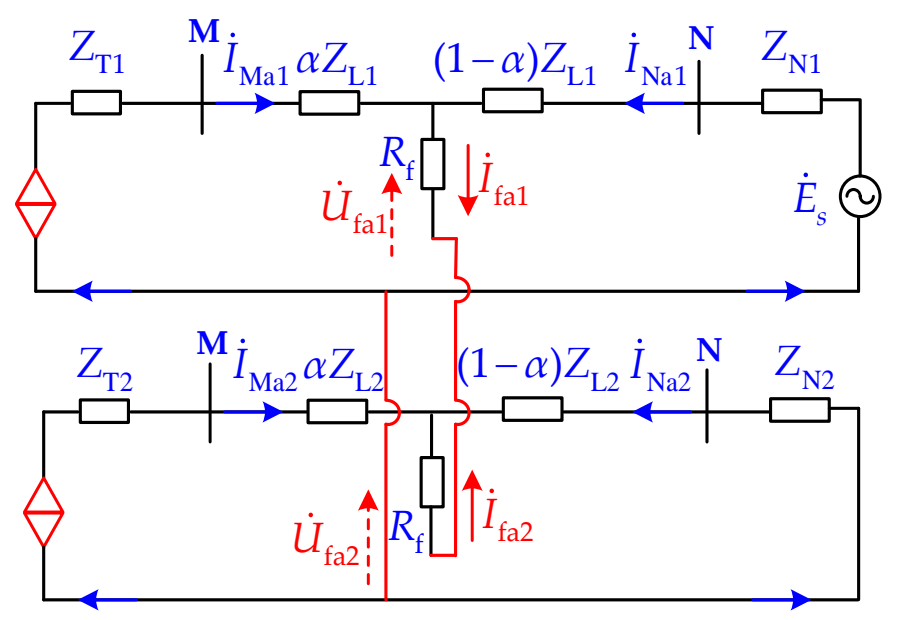

Figure 3. Sequence network diagram under a phase-B-to-phase-C (BC) fault at $f_{1}$.

In case of a phase B-to-phase $C$ fault, the fault current contains positive- and negative-sequence currents. According to Equation (3), the fault currents of phases B and C on the M-side can be calculated as

$$
\begin{aligned}
& \dot{I}_{\mathrm{Mb}}=\dot{I}_{\mathrm{Mb} 1}+\dot{I}_{\mathrm{Mb} 2}=I_{\mathrm{Mm} 1} \measuredangle\left(\delta_{1}+\varphi-120^{0}\right)+k_{\mathrm{pq}} k_{\mathrm{u}} I_{\mathrm{Mm} 1} \measuredangle\left(\delta_{2}+\varphi+120^{0}\right) \\
& \dot{I}_{\mathrm{Mc}}=\dot{I}_{\mathrm{Mc} 1}+\dot{I}_{\mathrm{Mc} 2}=I_{\mathrm{Mm} 1} \measuredangle\left(\delta_{1}+\varphi+120^{0}\right)+k_{\mathrm{pq}} k_{\mathrm{u}} I_{\mathrm{Mm} 1} \measuredangle\left(\delta_{2}+\varphi-120^{0}\right)
\end{aligned} .
$$

Owing to the fragility of the power electronic devices and the weak infeed characteristic of the PVPPs, the fault currents on the M-side are lower than those in the conventional power grid system. According to Figure 3, the fault current expressions of phases B and C on the $\mathrm{N}$-side can be calculated as

$$
\dot{I}_{\mathrm{Nb}}=-\dot{I}_{\mathrm{Nc}} \approx \dot{I}_{\mathrm{fb}}=-\mathrm{j} \frac{\sqrt{3} \dot{U}_{\mathrm{f}|0|}}{\mathrm{Z}_{\sum 1}+\mathrm{Z}_{\sum 2}+2 \mathrm{R}_{\mathrm{f}}}=\frac{\sqrt{3} U_{\mathrm{f}|0|}}{\left|\mathrm{Z}_{\Sigma}^{\mathrm{BC}}\right|} \measuredangle-\left(\theta_{\mathrm{Z}-\mathrm{BC}}+90^{0}\right),
$$

where $\left|Z_{\Sigma}^{\mathrm{BC}}\right|$ and $\theta_{\mathrm{Z}-\mathrm{BC}}$ are the total impedance and impedance angle of the $\mathrm{BC}$ fault network, respectively.

\section{Performance Analysis of Current Differential Protection}

Based on the previous discussion of the fault current analysis on $\mathrm{M}$ - and $\mathrm{N}$-side of the transmission line, the performance of current differential protection will be studied in detail in Section 3. The protection criterion of current differential protection is defined $[20,21]$ as

$$
\begin{gathered}
\left|\dot{I}_{\mathrm{M} x}+\dot{I}_{\mathrm{N} x}\right|>I_{\mathrm{set}} \\
\underbrace{\left|\dot{I}_{\mathrm{M} x}+\dot{I}_{\mathrm{N} x}\right|}_{I_{\mathrm{op} x}}>K \mid \underbrace{\left|\dot{I}_{\mathrm{M} x}-\dot{I}_{\mathrm{N} x}\right|}_{I_{\mathrm{res} x}},
\end{gathered}
$$

where $I_{\text {set }}$ is the threshold value of the differential current and $I_{\text {opx }}$ and $I_{\text {resx }}$ are the differential current and restraint current of the $\mathrm{x}$-phase, respectively. $K$ is the restraint coefficient, which is generally 0.8 .

\subsection{Operating Performance Analysis of Current Differential Protection under Internal Ground Faults}

In this section, the performance of current differential protection is studied by taking internal AG fault as an example. By simplifying Equation (8), the mathematical expression of phase-A current on the M-side can be obtained:

$$
\dot{I}_{\mathrm{Ma}}=I_{\mathrm{Mvsc}} \measuredangle \varphi_{\mathrm{vsc}}+C_{\mathrm{M} 0} I_{\mathrm{f} 0 \_\mathrm{AG}} \measuredangle-\theta_{\mathrm{Z}-\mathrm{AG}}
$$


where

$$
\begin{gathered}
I_{\mathrm{Mvsc}}=I_{\mathrm{Mm} 1} \sqrt{1+k_{\mathrm{pq}}^{2} k_{\mathrm{u}}^{2}+2 k_{\mathrm{pq}} k_{\mathrm{u}} \cos \left(\delta_{1}-\delta_{2}\right)} \\
\varphi_{\mathrm{vsc}}=\tan ^{-1} \frac{\sin \left(\delta_{1}+\varphi\right)+k_{\mathrm{pq}} k_{\mathrm{u}} \sin \left(\delta_{2}+\varphi\right)}{\cos \left(\delta_{1}+\varphi\right)+k_{\mathrm{pq}} k_{\mathrm{u}} \cos \left(\delta_{2}+\varphi\right)} \\
I_{\mathrm{f} 0 \_\mathrm{AG}}=\frac{U_{\mathrm{f}|0|}}{\left|\mathrm{Z}_{\Sigma}^{\mathrm{AG}}\right|}
\end{gathered} .
$$

Equations (4) and (14) show that the fault currents of M-side are considerably influenced by many factors, including the control system parameters, line impedance, zero-sequence voltage, and grid voltage imbalance coefficient.

From Equations (9), (12), and (13), the ratio of differential current over restraint current $\left(K_{\mathrm{a}}\right)$ can be given by

$$
\begin{aligned}
K_{\mathrm{a}}=\frac{I_{\mathrm{opa}}}{I_{\mathrm{resa}}}= & \frac{\left|1 \measuredangle \varphi_{\mathrm{vsc}}+3 K_{\mathrm{vsc} 0} \measuredangle-\theta_{\mathrm{Z}-\mathrm{AG}}\right|}{\left|1 \angle \varphi_{\mathrm{vsc}}+\left(2 C_{\mathrm{M} 0}-3\right) K_{\mathrm{vsc}} \angle-\theta_{\mathrm{Z}-\mathrm{AG}}\right|} . \\
& K_{\mathrm{vsc} 0}=\frac{I_{\mathrm{f} 0} \mathrm{AG}}{I_{\mathrm{Mvsc}}}
\end{aligned}
$$

Here, when $K_{\mathrm{a}}>0.8$, the current differential protection can perform well, whereas the current differential protection will operate inaccurately when $K_{a}<0.8$. At $K_{a}=0.8$, the current differential protection is at the edge of its operation.

According to the above analysis, $I_{\mathrm{f} 0 \_\mathrm{AG}}$ is much larger than $I_{\mathrm{Mvsc}}$, i.e., $K_{\mathrm{vsc} 0}>>1$. Generally, when the power grid system is weak, $K_{\mathrm{vsc} 0}$ may be equal to 2 . However, when the power grid system is strong, $K_{\mathrm{vsc} 0}$ may be equal to 12 . According to (14), $\varphi_{\mathrm{vsc}}$ may range between $-90^{\circ}$ and $90^{\circ}$. Based on the most possible conditions, the following assumptions were applied: (1) the amplitude ratio of the zero-sequence current to the fault current: $2 \leq K_{\mathrm{vsc} 0} \leq 12$; and (2) the phase angle of fault current: $-90^{\circ}$ $<\varphi_{\mathrm{vsc}}<90^{\circ}$. Meanwhile, $K_{\mathrm{vsc} 0}$ and $\varphi_{\mathrm{vsc}}$ are within a reasonable range, which covers most cases.

The ratio of differential current over the restraint current $\left(K_{\mathrm{a}}\right)$ under an internal AG fault is depicted in Figure 4, which shows that $K_{\mathrm{a}}$ is influenced by $K_{\mathrm{vsc} 0}$ and $\varphi_{\mathrm{vsc}}$. Upon comparing different values of $K_{\mathrm{vsc} 0}$ and $\varphi_{\mathrm{vsc}}$, we can observe that $K_{\mathrm{a}}$ changes in accordance with the changes in $K_{\mathrm{vsc} 0}$ and $\varphi_{\mathrm{vsc}}$. However, irrespective of the changes in $K_{\mathrm{vsc} 0}$ and $\varphi_{\mathrm{vsc}}$, the ratio of the differential current over restraint current is always greater than 1 . Therefore, the current differential protection can operate reliably.

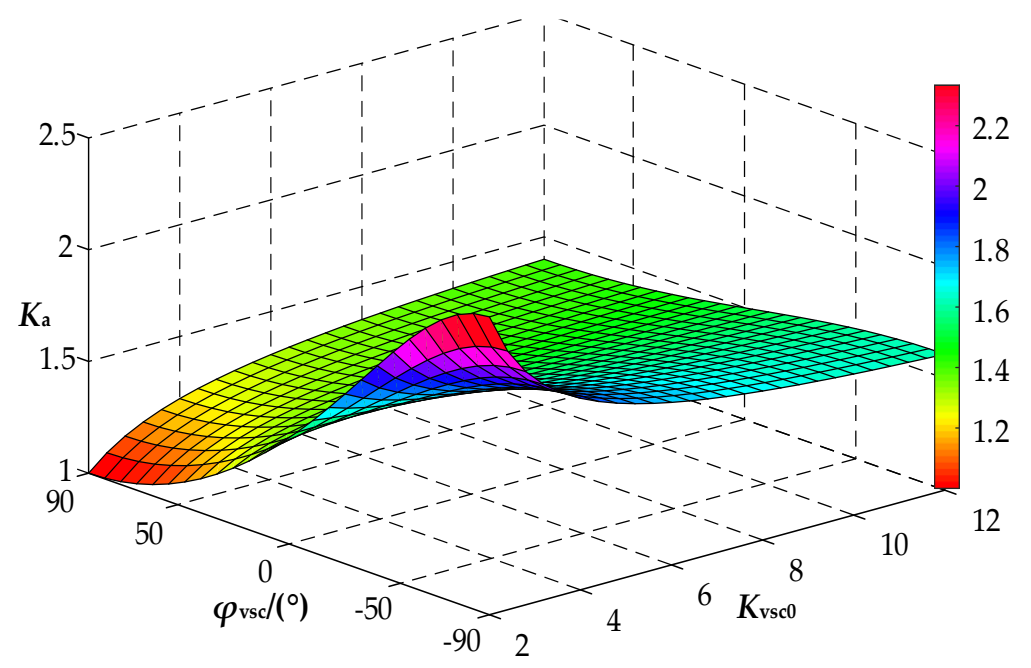

Figure 4. Ratio of differential current over restraint current under an internal AG fault.

This section considers AG fault as a case to analyze the influence of PVPPs on current differential protection. The analytic processes and conclusions of the current differential protection for AG fault can also be applied to other asymmetric ground faults. Because of space limitations, the analytic process will not be repeated. 


\subsection{Operating Performance Analysis of Current Differential Protection under Internal Ungrounded Faults}

In this section, the performance problem of current differential protection is studied by taking internal BC fault as an example. By simplifying Equation (10), the phasor expression of fault-phase (phase-B, C) current on the M-side can be obtained as

$$
\dot{I}_{\mathrm{Mb}}=I_{\mathrm{Mb}} \measuredangle \varphi_{\mathrm{Mb}}, \dot{I}_{\mathrm{Mc}}=I_{\mathrm{Mc}} \measuredangle \varphi_{\mathrm{Mc}},
$$

where

$$
\begin{gathered}
I_{\mathrm{Mb}, \mathrm{c}}=I_{\mathrm{Mm} 1} \sqrt{1+k_{\mathrm{pq}}^{2} k_{\mathrm{u}}^{2}+2 k_{\mathrm{pq}} k_{\mathrm{u}} \cos \left(\delta_{1}-\delta_{2} \pm 120^{0}\right)} \\
\varphi_{\mathrm{Mb}, \mathrm{c}}=\tan ^{-1} \frac{\sin \left(\delta_{1}+\varphi \mp 120^{0}\right)+k_{\mathrm{pq}} k_{\mathrm{u}} \sin \left(\delta_{2}+\varphi \pm 120^{\circ}\right)}{\cos \left(\delta_{1}+\varphi \mp 120^{0}\right)+k_{\mathrm{pq}} k_{\mathrm{u}} \cos \left(\delta_{2}+\varphi \pm 120^{\circ}\right)}
\end{gathered}
$$

As shown in Equations (4) and (17), the amplitude and phase angle of the fault currents are considerably affected by many factors such as the control system parameters and grid voltage imbalance coefficient.

By substituting Equations (11), (16), and (17) into Equation (12), the ratio of differential current over restraint current $\left(K_{\mathrm{b}}\right.$ and $\left.K_{\mathrm{c}}\right)$ can be expressed as follows:

$$
\begin{gathered}
K_{\mathrm{b}}=\frac{I_{\mathrm{opb}}}{I_{\text {resb }}}=\frac{\left|1 \measuredangle \varphi_{\mathrm{Mb}}+K_{\mathrm{vscb}} \measuredangle-\left(\theta_{\mathrm{Z}-\mathrm{BC}}+90^{0}\right)\right|}{\left|1 \measuredangle \varphi_{\mathrm{Mb}}-K_{\mathrm{vscb}} \measuredangle-\left(\theta_{\mathrm{Z}-\mathrm{BC}}+90^{0}\right)\right|} \\
K_{\mathrm{c}}=\frac{I_{\mathrm{opc}}}{I_{\mathrm{resc}}}=\frac{\left|1 \measuredangle \varphi_{\mathrm{Mc}}+K_{\mathrm{vscc}} \measuredangle\left(90^{0}-\theta_{\mathrm{Z}-\mathrm{BC}}\right)\right|}{\left|1 \measuredangle \varphi_{\mathrm{Mc}}-K_{\mathrm{vscc}} \measuredangle\left(90^{0}-\theta_{\mathrm{Z}-\mathrm{BC}}\right)\right|}
\end{gathered}
$$

Here, when $K_{\mathrm{b}, \mathrm{c}}>0.8$, the current differential protection can perform well, whereas when $K_{\mathrm{b}, \mathrm{c}}<$ 0.8 , the current differential protection will operate incorrectly. When $K_{\mathrm{b}, \mathrm{c}}=0.8$, the current differential protection is at the edge of its operation.

$K_{\mathrm{vscb}}$ and $K_{\mathrm{vscc}}$ are the ratios of phase-B, C fault current amplitude on the N-side to the B, C-phase fault current amplitude on the M-side, respectively. $K_{\mathrm{vscb}}$ and $K_{\mathrm{vscc}}$ can be expressed as follows:

$$
\begin{gathered}
K_{\mathrm{vscb}}=I_{\mathrm{fb}} / I_{\mathrm{Mb}}, K_{\mathrm{vscc}}=I_{\mathrm{fc}} / I_{\mathrm{Mc}} \\
I_{\mathrm{fb}}=I_{\mathrm{fc}}=\frac{\sqrt{3} U_{\mathrm{ff}|0|}}{\left|\mathrm{Z}_{\Sigma}^{\mathrm{BC}}\right|} .
\end{gathered}
$$

According to Equation (18), when the current phase angle difference on both sides of the transmission line is an acute angle, the differential current must be greater than the restraint current; hence, the current differential protection can perform well. When the current phase angle difference on both sides of the transmission line is an obtuse angle, the current differential protection may operate incorrectly. Therefore, the current phase angle difference is analyzed below in detail. According to (10) and (11), current phase angle difference is influenced by control system parameters and fault conditions, which significantly increase the difficulty of theoretical analysis. Therefore, some reasonable assumptions are necessary. This paper analyzed current phase angle difference using control variate method. The following assumptions were adopted to simplify the analysis: (1) the active power references: 0.2 p.u. $\leq P^{*} \leq 0.9$ p.u. The $P^{*}$ is within a reasonable range, which covers most cases.

The current phase angle difference with the different active power references $\left(P^{*}\right)$ under the control target of eliminating the negative-sequence current is depicted in Figure 5. Figure 5 shows that as the active power references changes, the current phase angle difference changes accordingly. Consequently, in the event of some certain fault cases, the current phase angle difference will exceed $90^{\circ}$, which will cause the restraint current to be greater than the differential current, and make the current differential protection exhibit a high risk of malfunction or inoperability. 


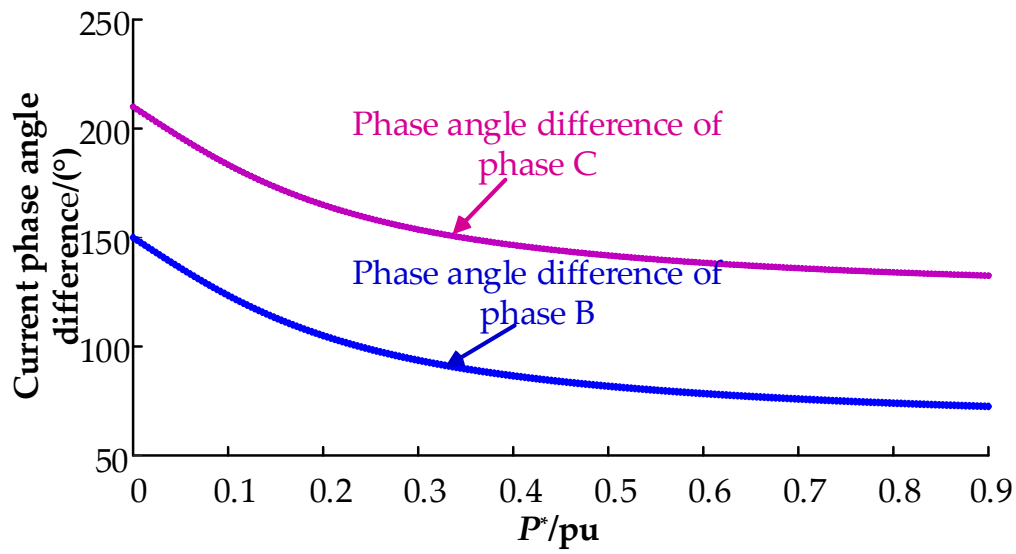

Figure 5. Current phase difference angle between both sides of the transmission line when the active power references change.

Generally, the amplitude of the N-side fault current is much larger than that of the M-side fault current. $K_{\mathrm{vscb}}$ and $K_{\mathrm{vscc}}$ are larger than 2 . Therefore, the following assumptions were adopted to simplify the analysis: (1) the active power references, i.e., 0.2 p.u. $\leq P^{*} \leq 0.8$ p.u., and (2) $2<K_{\mathrm{vscc}}$ $<10$. Meanwhile, $P^{*}$ and $K_{\mathrm{vscc}}$ are within a reasonable range, which can cover most fault conditions. Figure 6 shows the ratio of the differential current over restraint current $\left(K_{c}\right)$ under phase-to-phase fault. As showed in Figure 6, with the changes in the active power references and the strength of the power grid system, $K_{\mathrm{c}}$ may become less than 0.8 in some cases, which may further make the current differential protection perform incorrectly. Therefore, the current differential protection is considerably influenced by the interconnection of the PVPPs, which are likely to malfunction.

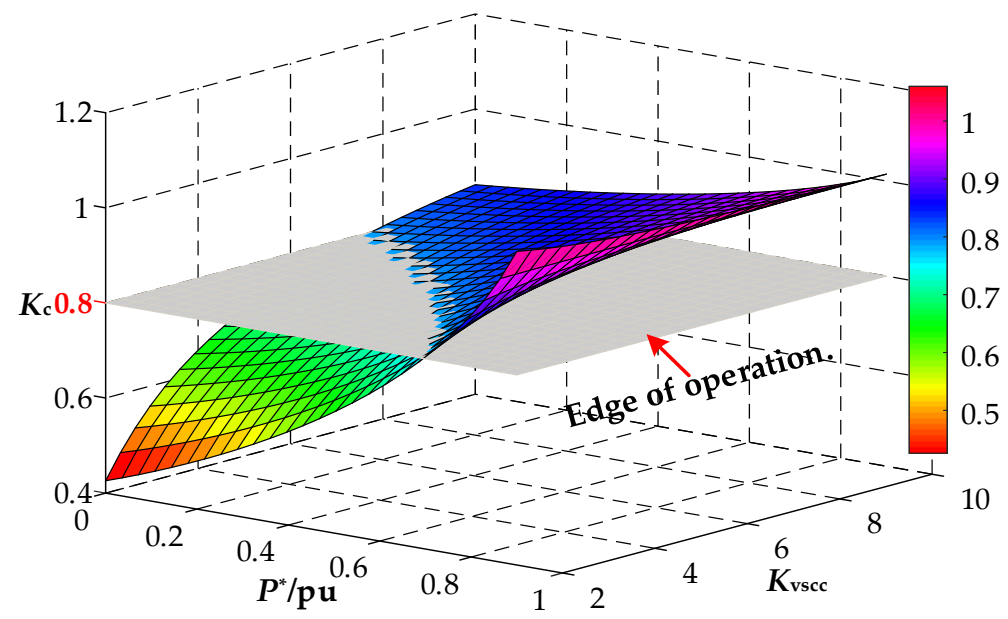

Figure 6. Ratio of the differential current over restraint current under a phase-to-phase fault.

In particular, assuming that the phase angle difference between the fault current phasors on both sides is $180^{\circ}$, the ratio of differential current over the restraint current is minimum, and Equation (18) can be expressed as follows:

$$
\frac{\left|1-K_{\mathrm{vscb}, \mathrm{c}}\right|}{\left|1+K_{\mathrm{vscb}, \mathrm{c}}\right|}=0.8 \Rightarrow K_{\mathrm{vscb}, \mathrm{c}}=9 .
$$

According to Equation (20), when the power grid system is extremely strong and the fault resistance is not large, the ratio of fault current amplitude on the $\mathrm{N}$-side to the fault current amplitude on the M-side is larger than 9 , and the current differential protection will operate reliably in any case. 


\subsection{Operating Performance Analysis of Current Differential Protection under External Faults}

In the event of the AG fault occurs in $f_{2}$, the fault phase currents on both the sides are observed to be equal in amplitude and opposite in direction. Thence, the phase-A current on the $\mathrm{M}$ - and $\mathrm{N}$-sides can be calculated as

$$
\dot{I}_{\mathrm{Ma}}=-\dot{I}_{\mathrm{Na}} .
$$

From Equations (12) and (21), the differential current and restraint current can be expressed as

$$
\begin{gathered}
I_{\mathrm{opa}}=\dot{I}_{\mathrm{Ma}}+\dot{I}_{\mathrm{Na}}=0 \\
I_{\mathrm{res} x}=\dot{I}_{\mathrm{Ma}}-\dot{I}_{\mathrm{Na}}=2 \dot{I}_{\mathrm{Ma}}
\end{gathered}
$$

Based on Equation (22), it is obvious that the differential current is less than the restraint current and that the ratio of the differential current over restraint current does not satisfy the operation criterion of current differential protection, which will not operate reliably.

\section{Simulation Verification}

To verify the accuracy and effectiveness of the aforementioned theoretical analysis, a study model of the PVPPs was built in PSCAD/EMTDC based on the actual engineering data, as depicted in Figure 1. Meanwhile, a digital signal processor (DSP) has been simulated via this PVPP simulation model. The data processing of the sampled values and the implementation of the control algorithm are programmed using the Fortran language, which can be used to simulate the interrupting mechanism of DSP and realize control algorithm digitization. The study model parameters of PVPP, the power grid system, the main transformer and the $220-\mathrm{kV}$ AC transmission line used in the simulation model are presented in Table 1.

Table 1. The study model parameters.

\begin{tabular}{cc}
\hline Component & Parameters \\
\hline PV power plant & $S_{\mathrm{PV}}=150 \mathrm{MVA}$ \\
\hline \multirow{2}{*}{ power grid system } & $\mathrm{Z}_{\mathrm{S} 1}=1.6+\mathrm{j} 18.26 \Omega$ \\
& $\mathrm{Z}_{\mathrm{S} 0}=3+\mathrm{j} 28.68 \Omega$ \\
\hline \multirow{3}{*}{ main transformer } & $S_{\mathrm{T}}=200 \mathrm{MVA}$ \\
& $k_{\mathrm{T}}=230 / 37 \mathrm{kV}$ \\
& $\mathrm{YNd} 11$ connection type \\
& short-circuit impedance $16 \%$ \\
\hline \multirow{2}{*}{$220 \mathrm{kV}$ transmission line } & $l_{\mathrm{MN}}=100 \mathrm{~km}$ \\
& $\mathrm{Z}_{\mathrm{L} 1}=10.7+\mathrm{j} 42.7 \Omega$ \\
& $\mathrm{Z}_{\mathrm{L} 0}=53.5+\mathrm{j} 115.3 \Omega$ \\
\hline
\end{tabular}

\subsection{Case 1: Internal Single-Phase-To-Ground Faults}

Figure 7 illustrates the simulation results of the internal AG fault occurs in $f_{1}$. The simulation waveforms of the fault current under the AG fault at $f_{1}$ are depicted in Figure 7a. It is demonstrated in Figure $7 \mathrm{a}$ that the fault current characteristics on the M-side are remarkably different from those of the $\mathrm{N}$-side. The fault current of the $\mathrm{M}$-side is mainly composed of a zero-sequence component, and the phase angles of the three-phase fault current are roughly the same. 


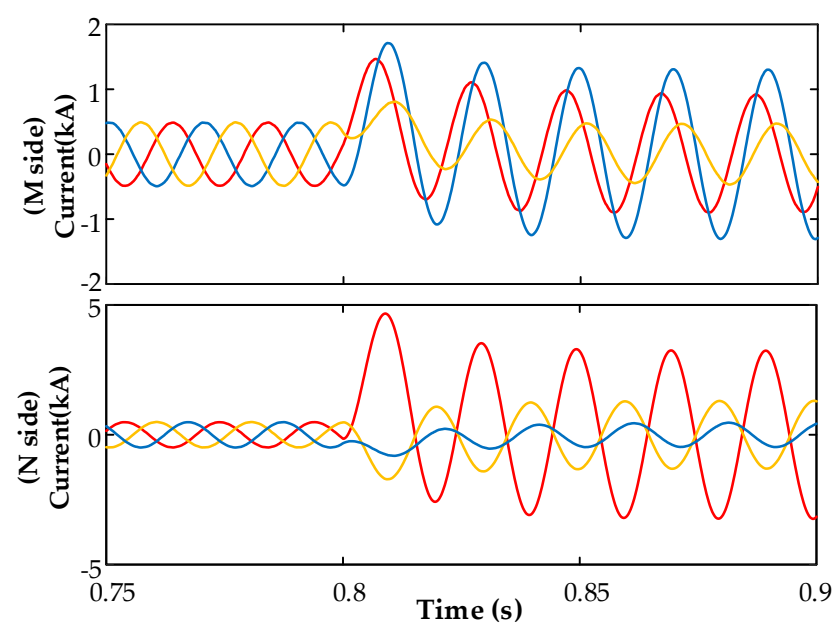

(a)

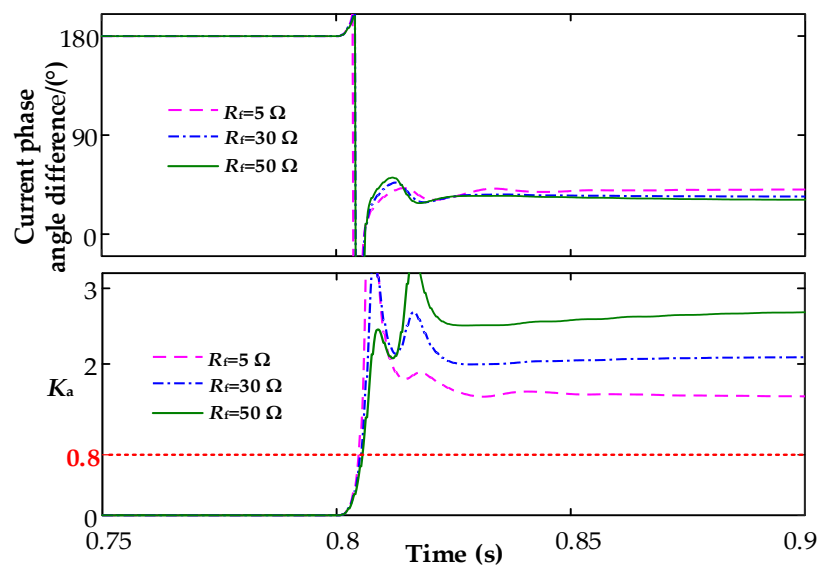

(b)

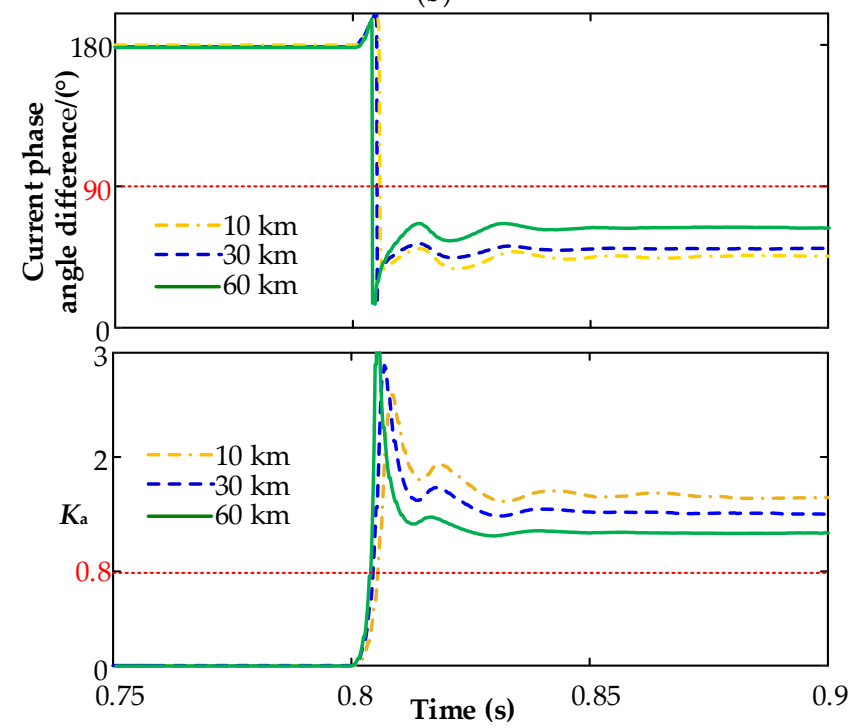

(c)

Figure 7. Simulation results under an internal AG fault. (a) Simulation waveforms of the fault current under an internal AG fault. (b) Operating characteristics of the current differential protection with different fault resistances under an internal AG fault. (c) Operating characteristics of the current differential protection with different fault locations under an internal AG fault.

The operating characteristics of the current differential protection with different fault resistances under the AG fault are illustrated in Figure $7 \mathrm{~b}$. By comparing different fault resistance values, the 
current phase angle difference is an acute angle in all the cases. Meanwhile, the ratio of the differential current over the restraint current $\left(K_{\mathrm{a}}\right)$ is much larger than 0.8 ; therefore, the current differential protection can perform well.

The operating characteristics of the current differential protection with different fault locations under AG fault are presented in Figure 7c. When the fault distance changes, the current phase angle difference is an acute angle, and the $K_{\mathrm{a}}$ is much larger than 1 . Therefore, the current differential protection can perform well.

In this section, the internal $\mathrm{BC}$ fault is considered to analyze the operating characteristics of the current differential protection based on different influencing factors. Figure 8 demonstrates that the current differential protection may operate incorrectly under an internal BC fault. Therefore, the simulation results of the current differential protection are consistent with the theoretical analysis results presented in Section 3.

\subsection{Case 2: Internal Phase-To-Phase Faults}

Figure 8 illustrates the simulation results of the internal $B C$ fault occurs in $\mathrm{f}_{1}$. The simulation waveforms of fault current under the BC fault are illustrated in Figure 8a. As can be seen from Figure 8, there is no negative sequence current for the fault current on the $\mathrm{M}$ side of the transmission line; furthermore, the three-phase current of the $\mathrm{M}$ side is symmetrical, and its amplitude does not exceed 1.2 times the rated value, which differs greatly from the fault current of the $\mathrm{N}$-side.

Figure $8 \mathrm{~b}$ illustrates the operating characteristics of the current differential protection with different fault resistances under the $B C$ fault. According to the simulation result observed in Figure $8 b$, as the fault resistance continuously changes, the current phase angle difference may be an obtuse angle, and then the ratio of the differential current over restraint current $\left(K_{c}\right)$ may be less than 0.8 , which may further cause current differential protection to operate inaccurately.

The operating characteristics of current differential protection with different system parameters is depicted in Figure 8c. The system parameter 1 denotes the equivalent positive-sequence impedance $\left(Z_{\mathrm{s} 1}\right)$ and zero-sequence impedance $\left(Z_{\mathrm{s} 0}\right)$ of the power grid system as $0.56+\mathrm{j} 6.98 \Omega$ and $2.3+\mathrm{j} 18.46$ $\Omega$, respectively; the system parameter 2 denotes $Z_{\mathrm{s} 1}$ and $Z_{\mathrm{s} 0}$ as $3.6+\mathrm{j} 43.86 \Omega$ and $4.2+\mathrm{j} 56.85 \Omega$, respectively; and the system parameter 3 denotes $Z_{\mathrm{s} 1}$ and $Z_{\mathrm{s} 0}$ as $5.6+\mathrm{j} 62.77 \Omega$ and $4.87+\mathrm{j} 78.89 \Omega$, respectively. As illustrated in Figure $8 c$, the current phase angle difference will exceed $90^{\circ}$ in all the cases and increases as the equivalent impedance of the power grid system increases, whereas the $K_{\mathrm{c}}$ gradually decreases. Meanwhile, Figure $8 \mathrm{c}$ illustrates that the current phase angle difference of phase-C is an obtuse angle under a BC fault, which causes a malfunction of the current differential protection in case of the power grid system is weak. In case of the power grid system is strong, the current differential protection will operate reliably; however, this may lead to low sensitivity.

The operating characteristics of the current differential protection with different active power references under BC fault with $5-\Omega$ fault resistance is depicted in Figure $8 \mathrm{~d}$. As the active power references increases, the current phase angle difference of phase- $C$ is an obtuse angle, and $K_{\mathrm{c}}$ will be less than 0.8 . Therefore, the current differential protection will operate incorrectly.

The operating characteristics of the current differential protection with different fault locations under the BC fault is depicted in Figure 8e. As the fault distance changes, $K_{\mathrm{b}}$ is always observed to be greater than 1 . However, as the distance between the bus $\mathrm{M}$ and the fault location decreases, $K_{\mathrm{c}}$ also gradually decreases. In particular, where the distance between bus $\mathrm{M}$ and the fault location is $10 \mathrm{~km}$, $K_{\mathrm{c}}$ will be less than 0.8 , and the current differential protection will operate incorrectly.

This section considers internal BC fault as a case to analyze the operating characteristics of the current differential protection with different influencing factors. It can be seen from Figure 8 that the current differential protection may operate incorrectly under an internal BC fault. Therefore, the simulation results of the current differential protection are consistent with the theoretical analysis results presented in Section 3. 

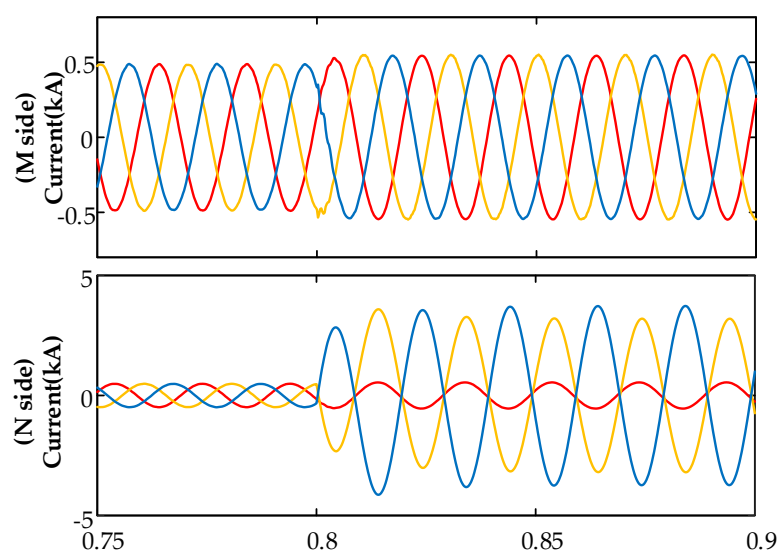

(a)

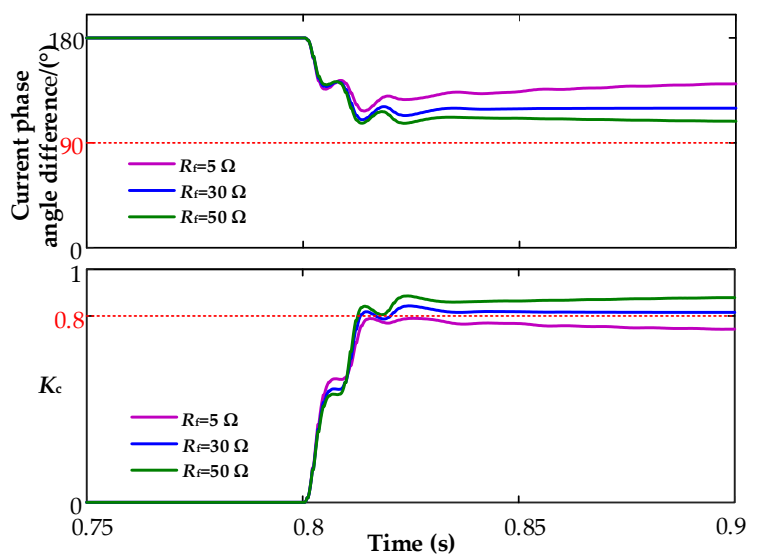

(b)

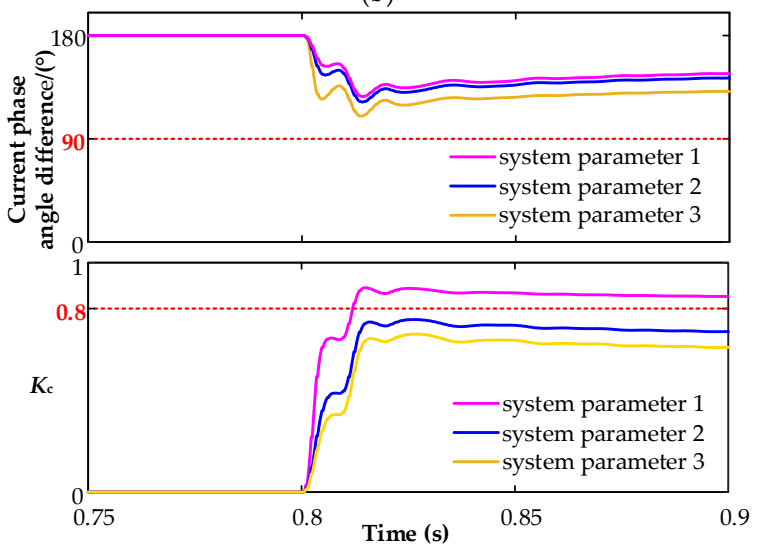

(c)

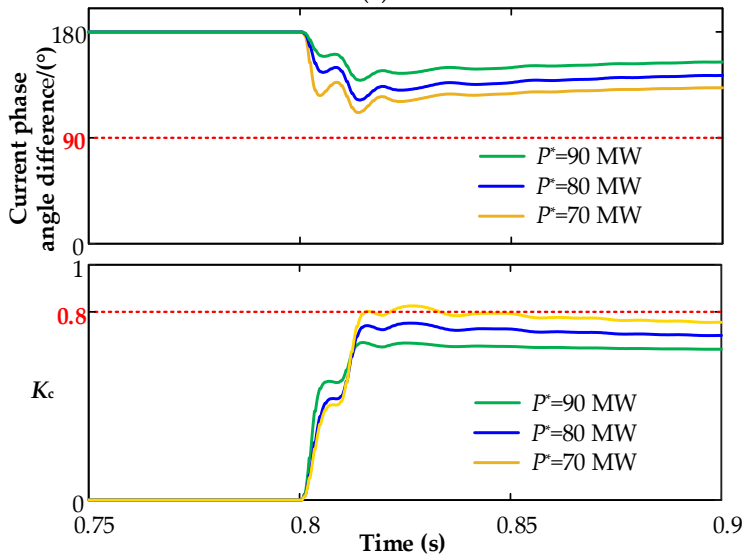

(d)

Figure 8. Cont. 


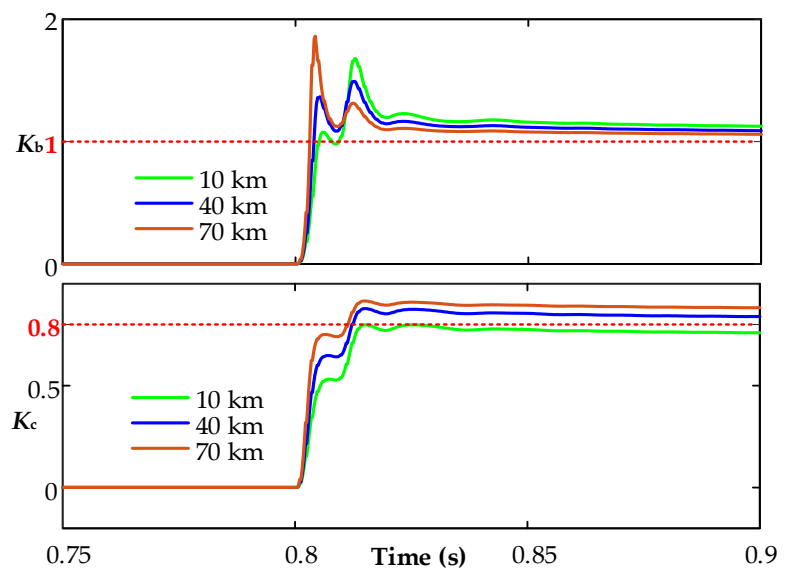

(e)

Figure 8. Simulation results under an internal BC fault. (a) Simulation waveforms of the fault current under an internal BC fault. (b) Operating characteristics of current differential protection with different fault resistances under an internal BC fault. (c) Operating characteristics of current differential protection with different system impedances under an internal BC fault. (d) Operating characteristics of current differential protection with different active power references under an internal BC fault. (e) Operating characteristics of current differential protection different fault locations under an internal BC fault.

\subsection{Case 3: External Faults}

The simulation results under an external AG fault occurring at $f_{2}$ are showed in Figure 9 . When fault type is an external AG fault, the current phase angle difference is almost $-180^{\circ}$, and the $K_{\mathrm{a}}$ is almost equal to 0 . The amplitude of the fault phase currents on both sides is almost equal, and the directions are opposite; thence, the current differential protection will not operate reliably. Similarly, the simulation results of the current differential protection in case of the AG fault is also applicable to other fault types.

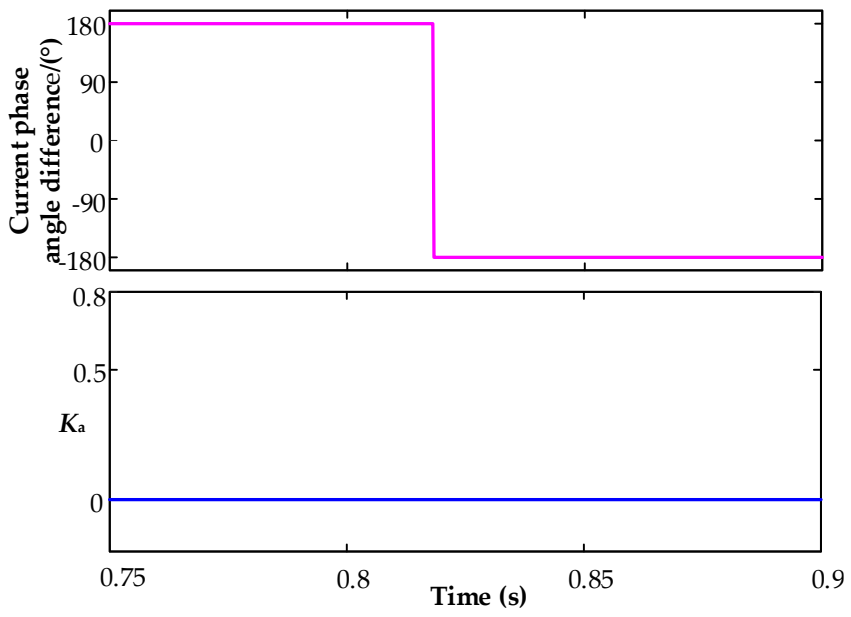

Figure 9. Simulation results under an external AG fault occurring at $f_{2}$ on the transmission line.

\section{Discussion}

With the maturity of the inverter integration technology and the commissioning of large-scale PVPPs, investigating the performance problem of current differential protection on high-voltage transmission lines is of great significance to power grid. The main contributions of the present study are as follows:

1. Some studies have investigated the influence of the renewable energy power stations on current differential protection [24-28]. However, those studies did not discuss or analyze the specific 
fault characteristics of PVPPs from a mathematical viewpoint. Compared with previous studies, this study is the first to analyze the influence of PVPPs on the current differential protection of the AC transmission lines based on mathematical theory and summarizes its influencing factors based on analytical expressions.

2. The ratio of differential current over restraint current was initially derived in this study; this ratio is considerably affected by the control system parameters, power grid system parameters, fault resistance, and fault types. Furthermore, the dynamic characteristics of the ratio of differential current over restraint current can be clearly observed via a three-dimensional diagram.

3. The ratio of the fault-current amplitude on the $\mathrm{N}$-side with respect to the fault current amplitude on the M-side is larger than nine and the current differential protection will operate reliably in any case when the power grid system is extremely strong and the fault resistance is not large. Current differential protection may not operate correctly when the power grid system is weak. Therefore, the power grid system parameters will enhance the adverse influence of the PVPPs on current differential protection when the PVPPs are connected to a power grid.

4. This study provides meaningful guidance for the engineering application of current differential protection. Moreover, the analytic ideas presented in this study are suitable for other traditional fault protection, including directional relay protection and phase selection element protection.

5. This study mainly analyzed the effects of PVPPs on the performances of current differential protection. However, the solution to performance problems of current differential protection of the lines connected to PVPPs remains unmentioned, which is outside the scope of this research. The corresponding solution to eliminate the adverse effects of PVPPs on current differential protection is one of the authors' research focuses in the future.

\section{Conclusions}

The performance problem of current differential protection was analyzed in this paper. The following conclusions can be obtained related to the operation performance of current differential protection:

1. The ratio of differential current over restraint current has been derived in this study and is observed to be affected by the control system parameters, power grid system parameters, fault resistance, and fault types. Furthermore, the dynamic characteristics of this ratio can be clearly observed via a three-dimensional diagram. The current differential protection may not operate correctly with a change in the influencing factors.

2. This study reveals that the current differential protection exhibits a high risk of malfunction or inoperability in case the AC transmission lines are connected with the PVPPs. In case of a ground fault, the current phase angle difference is an acute angle, and the current differential protection can perform well. However, if the fault type is an ungrounded fault, the current phase angle difference may become an obtuse angle, which may cause the inaccurate operation of the current differential protection.

3. The mathematical analysis presents that the amplitude ratio of the fault current on both sides of the line is larger than nine and that the current differential protection will operate reliably in any case. Therefore, it is necessary to avoid the connection of large-scale PVPPs with weak grids.

4. Future power grids will comprise more photovoltaic power generators that pose a massive challenge to the traditional fault protection due to the overcurrent limits of the power electronic devices and the controllability of the PV inverter. A novel real-time intelligent adaptive current differential protection is a key research direction, and its restraint coefficient can be adaptively adjusted based on the capacity and operation mode of the power grid.

Author Contributions: Formal analysis, W.L.; Funding acquisition, Y.L.; Investigation, Y.L., W.L. and G.X.; Methodology, Y.L.; Supervision, Y.L.; Validation, W.L. and G.X.; Writing—original draft, G.X.; Writing一review and editing, Y.L. All authors have read and agreed to the published version of the manuscript. 
Funding: This study was supported by the National Natural Science Foundation of China (Grant No.51707193) and the Fundamental Research Funds for the Central Universities (2017QJ05).

Conflicts of Interest: The authors declare no conflicts of interest.

\section{References}

1. Kouro, S.; Leon, J.I.; Vinnikov, D.; Franquelo, L.G. Grid-connected photovoltaic systems: An overview of recent research and emerging PV converter technology. IEEE Ind. Electron. Mag. 2015, 9, 47-61. [CrossRef]

2. Ghiani, E.; Pilo, F. Smart inverter operation in distribution networks with high penetration of photovoltaic systems. J. Mod. Power Syst. Cle. 2015, 3, 50-511. [CrossRef]

3. Baburaj, K.; Salvador, C.; Josep, P. Maximum power point controller for large scale photovoltaic power plants using central inverters under partial shading conditions. IEEE T. Power Electr. 2019, 34, 3098-3109.

4. Jung, D.Y.; Ji, Y.H.; Park, S.H.; Jung, Y.C.; Won, C.Y. Interleaved soft-switching boost converter for photovoltaic power-generation system. IEEE T. Power Electr. 2011, 26, 1137-1145. [CrossRef]

5. Jia, J.; Yang, G.; Nielsen, A.H.; Rønne-Hansen, P. Impact of VSC control strategies and incorporation of synchronous condensers on distance protection under unbalanced faults. IEEE Trans. Ind. Electron. 2019, 66, 1108-1118. [CrossRef]

6. Song, H.; Kwanghee, N. Dual current control scheme for PWM converter under unbalanced input voltage conditions. IEEE T. Ind. Electron. 1999, 46, 953-959. [CrossRef]

7. Zhikang, S.; Chao, S.; Xin, Y.; Liu, X.; Shen, Z.J. Fault analysis of inverter-interfaced distributed generators with different control schemes. IEEE Trans. Power Deliv. 2018, 33, 1223-1235.

8. Kabiri, R.; Donald, G.H.; Brendan, P.M. Control of active and reactive power ripple to mitigate unbalanced grid voltages. IEEE Trans. Ind. Appl. 2016, 52, 1660-1668. [CrossRef]

9. Nagpal, M.; Charles, H. Impact of power-electronic sources on transmission line ground fault protection. IEEE T. Power Deliv. 2018, 33, 62-70. [CrossRef]

10. Chen, S.; Tai, N.; Fan, C.; Liu, J.; Hong, S. Adaptive distance protection for grounded fault of lines connected with doubly-fed induction generators. IET Gener. Transm. Dis. 2017, 11, 1513-1520. [CrossRef]

11. Bollen, M.; Hassan, F. Protection. In Integration of Distributed Generation in the Power System, 1st ed.; Hooshyar, A., Azzouz, M.A., El-Saadany, E.F., Eds.; Wiley: Hoboken, NJ, USA, 2011; pp. 299-366.

12. Wen, J.; Meiling, L.; Chenjie, G.; Hongsheng, W.; Bohan, L. Fault Transient Analysis and Protection Performance Evaluation within a Large-scale PV Power Plant. MATEC Web Conf. 2016, 77, 16008. [CrossRef]

13. Yingyu, L.; Guanjun, X.; Wenting, Z.; Cong, W. Adaptability analysis of fault component distance protection on transmission lines connected to photovoltaic power plants. Energies 2019, 12, 1578-1596.

14. Jia, K.; Gu, C.; Xuan, Z.; Li, L. Fault characteristics analysis and line protection design within a large-scale photovoltaic power plant. IEEE T. Smart Grid. 2018, 9, 4099-4108. [CrossRef]

15. Yan, K.; Zhang, B.; Zhang, W.; Huang, R.; Jin, X. Analysis and improvement of relay protection for photovoltaic power plant connected to grid. In Proceedings of the 2013 IEEE International Conference IEEE, Region 10 (TENCON 2013), Xi'an, China, 22 October 2013; pp. 1-4.

16. Li, B.; Yuan, Y.; Wei, L. Research on relay protection of grid-connected phtovoltaic power plant in the plateau. In Proceedings of the 2011 International Conference on Advanced Power System Automation and Protection, Beijing, China, 16-20 October 2011; pp. 1814-1818.

17. Fang, Y.; Jia, K.; Yang, Z.; Li, Y.; Bi, T. Impact of inverter-interfaced renewable energy generators on distance protection and an improved scheme. IEEE Trans. Ind. Electron. 2019, 66, 7078-7088. [CrossRef]

18. Hooshyar, A.; Azzouz, M.A.; El-Saadany, E.F. Distance protection of lines emanating from full-scale converter-interfaced renewable energy power plants-Part I: Problem statement. IEEE Trans. Power Deliv. 2015, 30, 1770-1780. [CrossRef]

19. Hooshyar, A.; Azzouz, M.A.; El-Saadany, E.F. Distance protection of lines emanating from full-scale converter-interfaced renewable energy power plants-part II: Solution description and evaluation. IEEE Trans. Power Deliv. 2015, 30, 1781-1791. [CrossRef]

20. Chen, Y.; Wen, M.; Yin, X.; Cai, Y.; Zheng, J. Distance protection for transmission lines of DFIG-based wind power integration system. Int. J. Electr. Power Energy Syst. 2018, 100, 438-448. [CrossRef] 
21. Muddebihalkar, S.V.; Jadhav, G.N. Analysis of transmission line current differential protection scheme based on synchronized phasor measurement. In Proceedings of the 2015 Conference on Power, Control, Communication and Computational Technologies for Sustainable Growth (PCCCTSG), Kurnool, India, 11-12 December 2015; pp. 21-25.

22. Wang, X.; Zhou, Z.; Liu, H. A transmission line current differential protection based on virtual restraint current. In Proceedings of the 2015 IEEE Power \& Energy Society General Meeting, Denver, CO, USA, 26-30 July 2015; pp. 1-4.

23. Miao, S.; Liu, P.; Lin, X. An adaptive operating characteristic to improve the operation stability of percentage differential protection. IEEE T. Power Deliv. 2010, 25, 1410-1417. [CrossRef]

24. Jia, K.; Li, Y.; Fang, Y.; Zheng, L.; Bi, T. Transient current similarity based protection for wind farm transmission lines. Appl. Energy 2018, 225, 42-51. [CrossRef]

25. Tripathy, L.N.; Jena, M.K.; Samantaray, S.R. Differential relaying scheme for tapped transmission line connecting UPFC and wind farm. Int. J. Elec. Power 2014, 60, 245-257. [CrossRef]

26. Han, B.; Li, H.; Wang, G. A Virtual Multi-Terminal current differential protection scheme for distribution networks with inverter-interfaced distributed generators. IEEE T Smart Grid. 2018, 9, 5418-5431. [CrossRef]

27. Chen, S.; Tai, N.; Fan, C.; Liu, J.; Hong, S. Sequence-component-based current differential protection for transmission lines connected with IIGs. IET Gener. Transm. 2018, 12, 3086-3096. [CrossRef]

28. Gao, H.; Juan, L.; Bingyin, X. Principle and implementation of current differential protection in distribution networks with high penetration of DGs. IEEE T. Power Deliv. 2017, 32, 565-574. [CrossRef]

29. Yazdani, A.; Iravani, R. A unified dynamic model and control for the voltage-sourced converter under unbalanced grid conditions. IEEE T. Power Deliv. 2006, 21, 1620-1629. [CrossRef]

(C) 2020 by the authors. Licensee MDPI, Basel, Switzerland. This article is an open access article distributed under the terms and conditions of the Creative Commons Attribution (CC BY) license (http://creativecommons.org/licenses/by/4.0/). 